\title{
Crotalaria paulinea, Novo Hospedeiro Natural do Vírus do Mosaico Severo do Caupi
}

\author{
J. Albersio A. Lima ${ }^{1 *}$, Aline Kelly Q. Nascimento ${ }^{1 *}$, Gilson Soares Silva², \\ Rosa Felícia E. A. Camarço ${ }^{1 *}$ \& M. Fátima B. Gonçalves ${ }^{1}$ \\ 'Laboratório de Virologia Vegetal, UFC, Campus do Pici, Fortaleza-CE, e-mail: albersio@ufc.br; \\ ${ }^{2}$ Universidade Estadual do Maranhão, São Luiz, MA
}

(Aceito para publicação em 08/06/2005)

Autor para correspondência: J. Albersio A. Lima

LIMA, J.A.A., NASCIMENTO, A.K.Q., SILVA, G.S. \& CAMARÇO, R.F.E.A. Crotalaria paulinea, novo hospedeiro natural do vírus do mosaico severo do caupi. Fitopatologia Brasileira 30:429-433. 2005.

\section{RESUMO}

Amostras foliares de Crotalaria paulinea apresentando mosaico foram coletadas em São Luiz, MA, e enviadas ao Laboratório de Virologia Vegetal da UFC. As amostras foram testadas por Elisa indireto, contra anti-soros para Cowpea aphid-borne mosaic virus (CABMV) e Cucumber mosaic virus (CMV) e por dupla difusão em àgar contra anti-soro para Cowpea severe mosaic virus (CPSMV). As amostras reagiram somente com o anti-soro para CPSMV, indicando ser $C$. paulinea mais um hospedeiro natural do vírus. Extratos das folhas de C. paulinea foram inoculados em plantas de caupi (Vigna unguiculata subsp. unguiculata) mantidas em casa de vegetação. Dez dias após a inoculação, as plantas passaram a exibir sintomas de mosaico e a presença do CPSMV foi confirmada por sorologia. Nos estudos de gama de hospedeiros, envolvendo oito espécies botânicas, o isolado de CPSMV obtido de C. paulinea (CPSMV-Cp) infetou sistemicamente somente cultivares de caupi. Estudos de reações de RT-PCR revelaram a presença de uma banda no gel de agarose de 594 pb para o CPSNV-Cp semelhante às de outros isolados de CPSMV. O CPSMV-Cp foi multiplicado em caupi cv. Pitiúba e purificado por clarificação com $n$-butanol, precipitação viral com PEG e ultracentrifugação. A preparação purificada apresentou um espectro de absorção ultravioleta típico de núcleoproteína com uma razão $\mathrm{A}_{260} / \mathrm{A}_{280}$ de 1,7 . Coelho da raça Nova Zelândia Branca imunizado com a preparação viral purificada, produziu anti-soro policlonal reativo com CPSMV em dupla difusão em àgar. Este é o primeiro relato sobre a infecção natural de CPSMV em C. paulinea.

Palavras-chave adicionais: Comovirus, CPSMV, caupi, Vigna unguiculata.

\section{ABSTRACT \\ Crotalaria paulinea, a new natural host of Cowpea severe mosaic virus}

Leaf samples from Crotalaria paulinea showing mosaic were collected in the city of São Luiz, MA and sent to the Plant Virus Laboratory at the UFC. The leaf samples were tested by indirect enzyme-linked immunosorbent assay (Elisa) against antisera specific to Cowpea aphid-borne mosaic virus (CABMV) and Cucumber mosaic virus (CMV) and by gel double-diffusion against antiserum to Cowpea severe mosaic virus (CPSMV). The samples reacted only with the antiserum to CPSMV indicating that $C$. paulinea is one more natural host of the virus. Leaf extracts from infected $C$. paulinea were mechanically inoculated in cowpea (Vigna unguiculata subsp. unguiculata) plants maintained in greenhouse. Ten days after inoculation, the plants started to exhibit mosaic and the presence of CPSMV was confirmed by serology. In a host range study involving eight plant species, the CPSMV isolate obtained from C. paulinea (CPSMV$\mathrm{Cp}$ ) infected only cowpea cultivars. The results of RT-PCR revealed a band in the agarose gel of $594 \mathrm{pb}$ for CPSMV-Cp similar to those of other CPSMV isolates. The CPSMV-Cp was increased in cowpea cv. Pitiuba and purified by clarification using $n$-butanol, virus particle precipitation with polyethylene glycol (PEG) and ultra centrifugation. The purified virus preparation presented an ultraviolet light absorption spectrum typical of nucleoprotein, with a ratio $\mathrm{A}_{260} / \mathrm{A}_{280}$ equal to 1.7. A White New Zealand rabbit immunized with the purified virus preparation produced polyclonal antiserum reactive to CPSMV in agar double-diffusion. This is the first report about natural infection of C. paulinea by CPSMV.

Additional keywords: Comovirus, CPSMV, cowpea, Vigna unguiculata.

O primeiro relato do vírus do mosaico severo do caupi (Cowpea severe mosaic virus CPSMV), família Comoviridae, gênero Comovirus, no Brasil foi realizado por Oliveira (1947) no Rio Grande do Sul. Desde então, a distribuição deste vírus alcançou todas as regiões produtoras de caupi, Vigna unguiculata (L.) Walp. subsp. unguiculata,

$\overline{* \text { Bolsistas do CNPq }}$ no país (Lima et al., 2005).

O caupi, também conhecido como feijão de corda e feijão macassar é uma leguminosa bem adaptada às condições brasileiras de clima e de solo, assumindo grande relevância social para o Nordeste. Existem vários fatores que podem implicar na redução da produtividade desta leguminosa em seus campos de cultivo, sendo as doenças ocasionadas por vírus, consideradas os principais fatores 
responsáveis pelos prejuízos. Dentre os vírus importantes que infetam caupi, destaca-se o CPSMV transmitido por mais de dez espécies de coleópteros (Lima et al., 2005).

O CPSMV infeta naturalmente várias espécies da família Leguminosae entre as quais: Canavalia brasiliensis Mart. Ex.Benth (Caner et al., 1969; Vasconcelos \& Lima, 1981), C. ensiformis DC. (Vasconcelos \& Lima, 1981), C. rosea (sw) DC (Caner et al., 1969), Centrosema pubescens Benth (Lin et al., 1982), Crotalaria juncea L. (Lin et al., 1982), Glycine $\max$ (L.) Merril (Anjos \& Lin, 1984; Souto et al., 2002), Lupinus albus L. (Caner et al., 1969), Macroptilium atropurpureum L. (Caner et al., 1969; Vasconcelos \& Lima, 1981), M. lathyroides (L.) Urban (Lima \& Nelson, 1977) M. panduratum Mart. Ex Benth., (Carner et al., 1969), Phaseolus lunatus L. (Caner et al., 1969), P. vulgaris L. (Cupertino et al., 1981), Psophocarpus tetragonolobus (L.) DC. (Kitajima et al., 1979), Pueraria sp. (Lin et al., 1982), Sesbania sp. (Caner et al., 1969), Vigna mungo L. (Lin et al., 1982), V. radiata (L.). R Wilezek (Brioso et al., 1994).

Crotalaria é um dos gêneros da família Leguminosae com cerca de 600 espécies distribuídas nas regiões trópicos e sub-trópicos. Na América do Sul, o Brasil é o país que apresenta a maior concentração de espécies do gênero, com aproximadamente 30 nativas. Dentre estas $C$. juncea é apontada como hospedeiro natural do CPSMV (Lin et al., 1982). O presente trabalho teve como objetivo isolar, identificar e caracterizar um vírus encontrado infetando $C$. paulinea Schrank no estado do Maranhão.

\section{Identificação sorológica}

Amostras foliares de $C$. paulinea apresentando sintomas de mosaico (Figura 1) provenientes do estado do Maranhão, foram testadas por "enzyme-linked immunosobant assay" (Elisa) indireto contra anti-soros específicos para Cowpea aphid-borne mosaic virus (CABMV), família Potyviridae, gênero Potyvirus e Cucumber mosaic virus (CMV), família Bromoviridae, gênero Cucumovirus. As amostras foram, também, testadas por dupla difusão em ágar contra anti-soro para CPSMV, no Laboratório de Virologia Vegetal da Universidade Federal do Ceará (UFC).

\section{Estudo de gama de hospedeiros}

Foram realizados estudos de gama de hospedeiros envolvendo oito espécies vegetais e 19 cultivares de caupi. Sementes de cada espécie ou cultivar foram plantadas em solo esterilizado, com quatro plantas por vaso, sendo quatro mantidas como testemunha. As inoculações foram realizadas seis a oito dias após o plantio, usando-se como inóculo extrato de plantas infetadas, preparado em solução tampão $0,05 \mathrm{M}$ de fosfato de potássio $\mathrm{pH} 7,5$. A sintomatologia foi observada por um período de 25 dias após a inoculação. Decorrido o período de observação foi realizado teste em dupla difusão em agar para todas as plantas inoculadas.

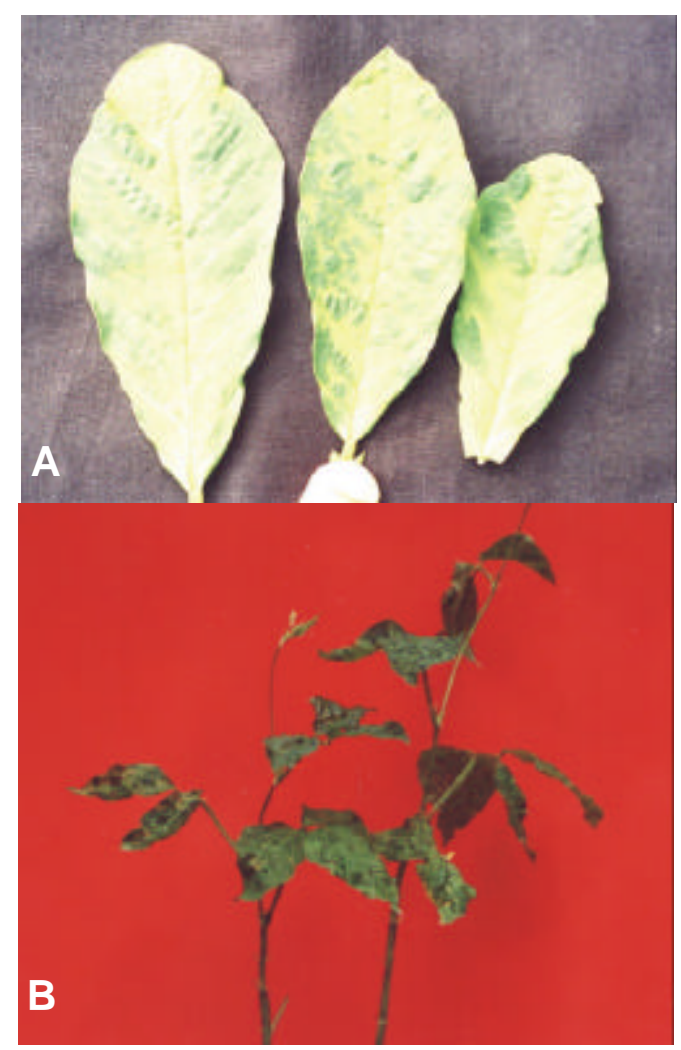

FIG. 1 - Sintomas induzidos pelo isolado de Cowpea severe mosaic virus (CPSMV) obtido de Crotalaria paulinea (CPSMV-Cp). AFolhas de $C$. paulinea naturalmente infetada com CPSMV-Cp exibindo mosaico típico; B- Plantas de caupi (Vigna unguiculata subsp. unguiculata) cv. Pitiúba artificialmente inoculadas com CPSMV-Cp exibindo mosaico severo e bolhosidade.

\section{Purificação do vírus e produção de anti-soro}

O vírus foi inoculado em 160 plantas sadias de caupi cv. Pitiúba e, decorrido um período de 18 dias, o material foliar foi coletado e usado para a purificação do vírus, seguindo o método usado por Lima \& Nelson (1974), com algumas adaptações. As partículas do vírus foram extraídas do material foliar na presença de tampão de fosfato de potássio $\mathrm{pH}$ 7,5 e, em seguida, o extrato foi clarificado com $8 \%$ de $n$-butanol, seguido de baixa centrifugação. O vírus foi precipitado com polietilenoglicol 6.000 (PEG) na presença de sulfito de sódio, seguido de centrifugações a $5.000 \mathrm{~g}$ por $60 \mathrm{~min}$. As partículas virais da preparação final foram submetidas a uma ultracentrifugação de $120.000 \mathrm{~g}$ durante 90 min e o precipitado foi ressuspendido em tampão de fosfato de potássio $0,05 \mathrm{M}, \mathrm{pH} 7,5$. A infetividade da preparação purificada do vírus foi testada através de inoculação em plantas sadias da cv. Pitiúba.

O vírus purificado foi utilizado para obtenção de antisoro policlonal em coelho da raça Nova Zelândia Branca, com aproximadamente seis meses de idade. A primeira sangria para obtenção do anti-soro foi realizada 30 dias após a primeira injeção e, a partir daí, o animal passou ser sangrado semanalmente. 


\section{Reação em cadeia de polimerase}

Para extração de RNAs totais, $100 \mu \mathrm{g}$ de tecido foliar fresco de planta de caupi infetada com o vírus isolado de $C$. paulionea foram triturados em nitrogênio líquido, conforme o método de extração RNeasy® Plant Kit protocol (Qiagen $\left.{ }^{\circledR}\right)$. O RNA do vírus foi retro-transcrito para a produção de seu respectivo cDNA. Para tanto, $5 \mu$ l de RNAs totais foram adicionados a $2 \mu 1$ de solução de primer antisenso: 5'-YTCRAAWCCVYTRTTKGGMCCACA-3' e $7 \mu 1$ de água ultra pura tratada com DEPC. A mistura foi submetida ao seguinte tratamento: aquecimento inicial a 42 ${ }^{\circ} \mathrm{C}$ por 2 min e resfriamento em gelo para adição dos componentes da reação: $5 \mu 1$ do tampão de transcrição reversa 5 x (200 mM Tris- $\mathrm{HCl}, \mathrm{pH} 8,4,500 \mathrm{mM} \mathrm{KCl}), 1,25$ $\mu 1$ da mistura de dNTPs ( $10 \mathrm{mM}$ de cada), $2 \mu 1$ de DTT $(0,1$ $\mathrm{M}$ ), e $0,75 \mu \mathrm{l}$ da enzima transcriptase reversa (Gibco BRL, $50 \mathrm{U} / \mu \mathrm{l})$. A mistura foi incubada a $50^{\circ} \mathrm{C}$ por $42 \mathrm{~min} \mathrm{e}$, em seguida, a $70{ }^{\circ} \mathrm{C}$ por $15 \mathrm{~min}$.

Os cDNAs foram submetidos a reação em cadeia de polimerase ("polymerase chain reaction", PCR) usando-se o "primer" antisenso e o primer senso: 5'-GCATGGTCCAC WCAGGT-3', correspondentes às seqüência de aminoácidos conservados presentes na sub-unidade do capsídeo dos vírus do gênero Comovirus (Souto et al., 2002). Para reação de PCR foi preparada uma solução contendo $0,5 \mu 1$ da mistura de dNTPs, $1 \mu \mathrm{l}$ de cada oligonucleotídeo, 0,5 $\mu \mathrm{l}$ da Taq DNA polimerase (Gibco-BRL $5 \mathrm{U} / \mu \mathrm{l}$ ), 2,5 $\mu \mathrm{l}$ de tampão $10 \mathrm{x}$ (200 $\mathrm{mM}$ Tris-HCl, $\mathrm{pH} 8,4,0,5 \mathrm{M} \mathrm{KCl}), 1,5 \mu 1$ de $\mathrm{MgCl}_{2}(25$ $\mathrm{mM}), 2,5 \mu \mathrm{l}$ do cDNA produzido e $15,5 \mu \mathrm{l}$ de água ultra pura. A mistura foi submetida a um ciclo inicial de $94{ }^{\circ} \mathrm{C} / 5$ min, $4{ }^{\circ} \mathrm{C} / 2$ min e $72{ }^{\circ} \mathrm{C} / 3$ min, seguido de 25 ciclos de 94 ${ }^{\circ} \mathrm{C} / 1 \mathrm{~min}, 41{ }^{\circ} \mathrm{C} / 2 \min$ e $72{ }^{\circ} \mathrm{C} / 3 \mathrm{~min}$, e um ciclo final de 72 ${ }^{\circ} \mathrm{C} / 7$ min. Alíquotas do produto da PCR foram analisadas por eletroforese em gel de agarose a $1,0 \%$, corados com brometo de etídio $(10 \mu \mathrm{g} / \mu \mathrm{l})$. De forma semelhante foram realizadas as reações de RT-PCR da estirpe CPSMV-Ce, comum no Estado do Ceará (Lima \& Nelson, 1977; Lima et al., 2005).

De acordo com os resultados dos testes sorológicos, as amostras reagiram somente com o anti-soro para CPSMV, indicando ser C. paulinea (Figura 1) mais um hospedeiro natural deste vírus. A ausência de reação com qualquer um dos outros anti-soros revelou, também, a inexistência da possibilidade de infecção mista com outros vírus.

Nos estudos de gama de hospedeiros, o vírus infetou 18 das 19 cultivares de caupi testadas, as quais apresentaram sintomas, variando de mosaico leve a mosaico severo, com bolhosidade (Tabela 1). As infecções virais e as ausências de infecção foram confirmadas por sorologia. $O$ vírus não infetou a cv. Macaibo de caupi, e nem as seguintes espécies vegetais: Cassia occidentalis L., Clitoria ternateae L., Leucaena sp., M. lathyroides, M. atropurpureum e Phaseolus membranescens L. Semelhantemente às demais estirpes do CPSMV, o isolado obtido de C. paulinea (CPSMV-Cp) ocasionou lesões locais em Chenopodium amaranticolor Coste \& Reyn (Tabela 1). Mesmo infetando a maioria das
TABELA 1 - Reações sintomatológicas e resultados sorológicos por dupla difusão em ágar apresentados por oito espécies vegetais e 19 cultivares de caupi (Vigna unguiculata) inoculadas com Cowpea severe mosaic virus (CPSMV) obtido de Crotalaria paulinea (CPSMV-Cp)

\begin{tabular}{lcc}
\hline \multirow{2}{*}{ Espécie vegetal / cultivar } & \multicolumn{2}{c}{ CPSMV - Cp } \\
\cline { 2 - 3 } & Sintoma* & Sorologia \\
\hline Cassia occidentalis & $\mathrm{S} / \mathrm{S}$ & - \\
Chenopodium amaranticolor & $\mathrm{LCL}$ & nao testado \\
Clitoria ternateae & $\mathrm{S} / \mathrm{S}$ & - \\
Leucaena sp. & $\mathrm{S} / \mathrm{S}$ & - \\
Macroptilium atropurpureum & $\mathrm{S} / \mathrm{S}$ & - \\
M. lathyroides & $\mathrm{S} / \mathrm{S}$ & - \\
Phaseolus membranescens & $\mathrm{S} / \mathrm{S}$ & - \\
Vigna unguiculata & & \\
'BR poty' & $\mathrm{Ml}$ & + \\
'CE 12' & $\mathrm{Ms}$ & + \\
'CE 36' & $\mathrm{Ms}, \mathrm{Bo}$ & + \\
'CE 40' & $\mathrm{Ms}, \mathrm{Bo}$ & + \\
'CE 43' & $\mathrm{Ms}, \mathrm{Bo}$ & + \\
'CE 44' & $\mathrm{M}$ & + \\
'CE 45' & $\mathrm{Ms}, \mathrm{Bo}$ & + \\
'CE 46 & $\mathrm{Ms}, \mathrm{Bo}$ & + \\
'CE 46' & $\mathrm{Ms}, \mathrm{Bo}$ & + \\
'CE 49' & $\mathrm{M}, \mathrm{Bo}$ & + \\
'CE 95' & $\mathrm{M}$ & + \\
'CE 315' & $\mathrm{M}$ & + \\
'CE 670' & $\mathrm{M}, \mathrm{Bo}$ & + \\
'Epace 92' & $\mathrm{M}$ & + \\
'Macaibo' & $\mathrm{S} / \mathrm{S}$ & + \\
'Otília' & $\mathrm{Ms}, \mathrm{Bo}$ & + \\
'Pitiúba' & $\mathrm{Ms}, \mathrm{Bo}$ & + \\
'Roxinho' & $\mathrm{M}, \mathrm{Bo}$ & + \\
'Setentão' & $\mathrm{Ml}, \mathrm{S} / \mathrm{Bo}$ & + \\
\hline
\end{tabular}

*Bo - Bolhosidade; LCL - Lesões cloróticas locais; Ml - Mosaico leve; M Mosaico; Ms - Mosaico severo; S/S - Sem sintomas

cultivares de caupi, observou-se uma grande diversidade de sintomas, indicativo da variabilidade genética do caupi ao CPSMV (Lima et al., 1992), o que facilitará o controle através do uso de genótipos resistentes (Lima et al., 2005).

Os resultados das reações de RT-PCR revelaram a presença de bandas predominantes no gel de agarose, correspondentes a $594 \mathrm{pb}$ para o CPSMV-Cp e a $596 \mathrm{pb}$ para o CPSMV-Ce (Figura 2), confirmando a identidade do CPSMV-Cp e sua similaridade genômica com o CPSMVCe. Segundo Brioso et al. (1996), com a utilização dos respectivos "primers", o tamanho do fragmento esperado para as estirpes de CPSMV é de, aproximadamente, 593 pb. Outros fragmentos observados no gel podem estar relacionados com as degenerescência dos "primers" ou com a temperatura de anelamento utilizada (Brioso et al., 1996).

A preparação purificada do vírus apresentou um espectro de absorção ultravioleta típico de núcleo proteína com uma razão $\mathrm{A}_{260} / \mathrm{A}_{280}$ de 1,7 , característico de vírus do gênero Comovirus. O rendimento final da preparação purificada foi estimado em $32,50 \mathrm{mg}$ de vírus por $\mathrm{Kg}$ de tecido foliar infetado. A infetividade das partículas virais purificadas foi confirmada em plantas sadias de caupi. O 
coelho imunizado com a preparação viral purificada produziu anti-soro policlonal reativo com CPSMV-Cp e outros isolados de CPSMV em dupla difusão em agar, apresentando fraca reação com extrato de plantas sadias, que deixo de ocorrer após sua diluição na proporção de 1:8 (Figura 3). O título do anti-soro em dupla difusão em agar foi estimado em 1:1024. Em testes de reciprocidade, o CPSMV-Cp mostrou-se sorologicamnete relacionado aos demais isolados do CPSMV, pertencente ao banco ativo de vírus do Laboratório de Virologia Vegetal da UFC, inclusive à estirpe que infeta a cv. Macaibo (CPSMV-Mc). Este constitui o primeiro relato sobre a infecção natural de CPSMV em C. paulinea.

O CPSMV apresenta uma larga variabilidade biológica (Lima et al., 1998; Lima et al., 2005), possuindo uma ampla gama de espécies hospedeiras, especialmente dentro da família Leguminosae, incluindo plantas nativas e cultivadas (Lima et al., 2005). Não constituindo as sementes

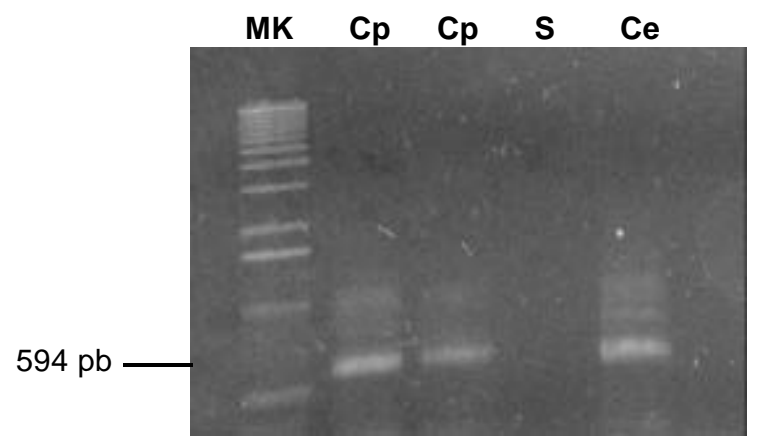

FIG. 2 - Produtos da transcrição reversa e reação em cadeia de polimerase (RT-PCR) de fragmentos do RNA-2, correspondentes às seqüências de aminoácidos conservados do capsídeo de um isolado de Cowpea severe mosaic virus (CPSMV) obtido de Crotalaria paulinea (CPSMV-Cp) e de um isolado do Ceará (CPSMV-Ce). MK - Marcadores de DNA 1,0 kb; Cp - Extrato de plantas de caupi (Vigna unguiculata sbp. unguiculata) infetada com CPSMV-Cp; Ce - Extrato de caupi infetado com CPSMV-Ce e $\mathrm{S}$ - Extrato de plantas de caupi sadias.

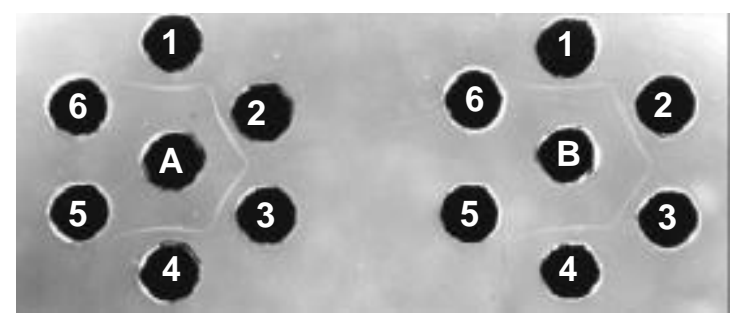

FIG. 3 - Teste de dupla difusão em agar com anti-soro para o isolado de Cowpea severe mosaic virus (CPSMV) obtido de Crotalaria paulinea (CPSMV- Cp). A) anti-soro para CPSMV$\mathrm{Cp}$; B) anti-soro para CPSMV isolado no Ceará (CPSMV-Ce); 1,2 extrato de plantas infetadas com CPSMV-Cp; 3,4 extrato de plantas infetadas com CPSMV-Ce; 5,6 extrato de planta sadia. de caupi fontes de inóculo do CPSMV (Assis Filho et al., 1992), as leguminosas hospedeiras nativas do Nordeste brasileiro, inclusive $C$. paulinea, devem desempenhar importante papel na sobrevivência e epidemiologia do vírus, funcionando como reservatórios naturais do mesmo, durante os períodos de estiagem.

Vários isolados de CPSMV, obtidos a partir de plantas de caupi naturalmente infetadas já foram caracterizados, destacando-se entre eles o CPSMV-Ce, do Ceará, estudado no início da década de 1970 (Lima \& Nelson, 1974, 1977), o CPSMV-Pi, do Piauí (Lima et al., 1998), o CPSMV-Pe, de Pernambuco (Lima et al., 1998) e o CPSMV-Mc obtido da cv. Macaibo imune a todos os outros isolados até o então avaliados no Laboratório de Virologia Vegetal da UFC (Lima et al., 1992).

\section{REFERÊNCIAS BIBLIOGRÁFICAS}

ANJOS, J.R.N. \& LIN, M.T. Bud Blight of soybeans caused by cowpea severe mosaic virus. Plant Disease 68:405- 407. 1984

ASSIS FILHO, F.M., LIMA, J.A.A., PIO-RIBEIRO, G. \& MARIANO, R.L.R. Ausência de transmissão por sementes do vírus do mosaico severo de caupi. Caderno Ômega 4:9-17. 1992.

BRIOSO, P.S.T., SANTIAGO, L.J.M., ANJOS, J.R.N. \& OLIVEIRA, D.E. Identificação de espécies do gênero Comovirus através de "polynerase chain reaction". Fitopatologia Brasileira 21:219-225. 1996.

BRIOSO, P.S.T., DUQUE, F.F., SAYÃO, F.A.D., LOURO, R.P., KITAJIMA, E.W \& OLIVEIRA, D.E. Vírus do mosaico severo do caupi - infeção natural em mungo verde, Vigna radiata. Fitopatologia Brasileira 19: 420-429. 1994.

CANER, J., SILBERSCHIMIDT, K.M. \& FLORES, E. Ocorrência do vírus do mosaico do Vigna no estado do São Paulo. O Biológico 35:13-16. 1969.

CUPERTINO, F.P., COSTA, C.L., LIN, M.T. \& KITAJIMA, E.W. Infecção natural do feijoeiro pelo vírus do mosaico severo do caupi no Centro-Oeste do Brasil. Fitopatologia Brasileira 6:529. 1981. (Resumo).

KITAJIMA, E.W., NODA, H., LIN, M.T. \& COSTA, C.L. Um mosaico em feijão-de-asa (Psophocarpus tetragonolobus) causado por um isolado do subgrupo severo do vírus do mosaico da Vigna. Fitopatologia Brasileira 4:519-528. 1979.

LIMA, J.A.A. \& NELSON, M.R. Etiology and epidemiology of mosaic of cowpea in Ceará, Brazil. Plant Disease 63:864-867. 1977.

LIMA, J.A.A. \& NELSON, M.R. Purificação e identificação sorológica de "cowpea mosaic virus" em Vigna sinensis Endl., no Ceará. Ciência Agronômica 3:5-8. 1974.

LIMA, J.A.A., LIMA, R.C.A., GONÇALVES, M.F.B. \& SITTOLIN, I.M. Biological and serological characteristics of a genetically different cowpea severe mosaic virus strain. Virus: Reviews and Research 3:57-65. 1998.

LIMA, J.A.A., SITTOLIN, I.M. \& LIMA, R.C.A. Diagnose e estratégias de controle de doenças ocasionadas por vírus. In: Freire Filho, F.R., Lima, J.A.A., Silva, P.H.S \& Ribeiro, V.Q. (Eds.) Feijão caupi: Avanços tecnológicos. Embrapa Informação Tecnológica. 2005. pp.404-459. 
LIMA, J.A.A., SITTOLIN. I.M., GONÇALVES, M.F.B. \& BRITO, E.M. Isolado do vírus do mosaico severo do caupi capaz de infetar a cultivar Macaibo. Fitopatologia Brasileira 17:186. 1992. (Resumo).

LIN, M.T., ANJOS, J.R.N. \& RIOS, G.P. Cowpea severe mosaic virus in five legumes in Central Brazil. Plant Disease 66:67-70. 1982.

OLIVEIRA, M.A. Contribuição ao estudo dos vírus causadores de mosaico no feijão macassar (Vigna spp). Instituto Agronômico do
Sul (Pelotas). Boletim Técnico 1:1-36. 1947.

SOUTO, E.R., ALMEIDA, A.M.R, ANÉSIO, B., FÁBIO, S. \& ÉBERSON S.C. Análise molecular de segmento do RNA-2 de Comovirus isolado de soja no estado do Paraná. Fitopatologia Brasileira 27:525-527. 2002.

VASCONCELOS, M.F.R. \& LIMA, J.A.A. Purificação e sorologia de raças de "cowpea severe mosaic virus" isoladas de 4 espécies de leguminosas. Fitopatologia Brasileira 6:534-534. 1981. (Resumo). 